\title{
A WEIGHTED COMPANION OF OSTROWSKI'S INEQUALITY USING THREE STEP WEIGHTED KERNEL
}

\author{
S. OBEIDAT, M. A. LATIF, AND A. QAYYUM
}

Received 10 December, 2018

\begin{abstract}
A weighted version of Ostrowski type integral inequalities is established. We use a newly developed special type of three steps kernel. Our findings give some new error bounds for various quadrature rules. We apply our results to cumulative distributive functions.
\end{abstract}

2010 Mathematics Subject Classification: 26D15; 26D20; 26D99

Keywords: Ostrowski inequality, weight function, composite quadrature rule, cumulative distributive function

\section{INTRODUCTION}

The importance of mathematical inequalities is due to its applications in several branches of Mathematics such as numerical integration, optimization theory, and integral operator theory. During the past few decades, many researchers worked on inequalities and their applications (see for instance [4]-[5], [7]-[8]).

In 1938, Ostrowski [6] introduced an interesting integral inequality which measures the deviation between a function and its integral mean. It is stated as follows:

Theorem 1. Let $f:[c, d] \rightarrow R$ be continuous on $[c, d]$ and differentiable on $(c, d)$, whose derivative $f^{\prime}:(c, d) \rightarrow R$ is bounded on $(c, d)$, i.e.

$$
\left\|f^{\prime}\right\|_{\infty}=\sup _{t \in[c, d]}\left|f^{\prime}(t)\right|<\infty
$$

then for all $x \in[c, d]$

$$
\left|f(x)-\frac{1}{d-c} \int_{c}^{d} f(t) d t\right| \leq\left[\frac{1}{4}+\left(\frac{x-\frac{c+d}{2}}{d-c}\right)^{2}\right](d-c)\left\|f^{\prime}\right\|_{\infty} .
$$

Another important inequality is so-called Grüss inequality [5] which links the integral mean of a product of two functions with the product of their integral means. It 
is stated as follows:

$$
\begin{aligned}
& \left|\frac{1}{d-c} \int_{c}^{d} f(x) g(x) d x-\frac{1}{d-c} \int_{c}^{d} f(x) d x \cdot \frac{1}{d-c} \int_{c}^{d} g(x) d x\right| \\
& \leq \frac{1}{4}\left(\alpha_{2}-\alpha_{1}\right)\left(\theta_{2}-\theta_{1}\right),
\end{aligned}
$$

where

$$
\alpha_{1} \leq f(x) \leq \alpha_{2} \text { and } \theta_{1} \leq g(x) \leq \theta_{2},
$$

for all $x \in[c, d]$. The constant $\frac{1}{4}$ is sharp in (1.2).

In [3], Dragomir and Wang combined Ostrowski and Grüss inequality and obtained a new inequality known in the literature as Ostrowski-Grüss type inequalities. Dragomir [2] established some companions of Ostrowski type integral inequalities.

In [1], Alomari proved the following companion inequality of Ostrowski's type using Grüss inequality.

Theorem 2. Let $f:[c, d] \rightarrow \mathbb{R}$ be a differentiable function on $(c, d),-\infty<c<$ $d<\infty$. If $f^{\prime} \in L^{1}[c, d]$ and $B_{1} \leq f^{\prime}(t) \leq B_{2}$ for all $t \in[c, d]$, where $B_{1}, B_{2}$ are constants, then the inequality

$$
\left|\frac{f(x)+f(c+d-x)}{2}-\frac{1}{d-c} \int_{c}^{d} f(t) d t\right| \leq \frac{1}{8}(d-c)\left(B_{2}-B_{1}\right)
$$

holds for all $x \in\left[c, \frac{c+d}{2}\right]$.

In the proof of Theorem 2, Alomari defined the following mapping

$$
p(x, t)=\left\{\begin{array}{cc}
t-c & t \in[c, x] \\
t-\frac{a+b}{2} & t \in(x, c+d-x] \\
t-b & t \in(c+d-x, d]
\end{array}\right.
$$

for all $x \in\left[c, \frac{c+d}{2}\right]$. The upper bound of Inequality (1.3) is obtained using the fact that

$$
x-\frac{c+d}{2} \leq p(x, t) \leq x-c
$$

for each $t \in[c, d]$ and each $x \in\left[c, \frac{c+d}{2}\right]$. However, this fact is not correct. For example, if $x=\frac{c+d}{2}-\frac{d-c}{100}$ and $t=\frac{c+d}{2}+\frac{d-c}{50}$, then

$$
p(x, t)=t-d=\frac{-12(d-c)}{25},
$$

and

$$
x-\frac{c+d}{2}=\frac{-(d-c)}{100}>p(x, t),
$$


which contradics Inequality (1.4). The correct property of $p(x, t)$ is that

$$
\min \left\{x-\frac{c+d}{2}, c-x\right\} \leq p(x, t) \leq \max \left\{\frac{c+d}{2}-x, x-c\right\} .
$$

for each $t \in[c, d]$ and each $x \in\left[c, \frac{c+d}{2}\right]$. Using this property of $p(x, t)$, the correction of Inequality (1.3) becomes

$$
\left|\frac{f(x)+f(c+d-x)}{2}-\frac{1}{d-c} \int_{c}^{d} f(t) d t\right| \leq \frac{1}{4}(d-c)\left(B_{2}-B_{1}\right) .
$$

In this paper, we will present a weighted version of Inequality (1.6) using a new three step kernel, and discuss some applications of our results. Throughout the present paper, a weight function (or density function) over some interval $[c, d]$, where $-\infty<c<d<\infty$, is a function $w:[c, d] \longrightarrow[0, \infty)$ with $0<\int_{c}^{d} w(t) d t<\infty$.

\section{MAIN RESULTS}

Definition 1. Let $-\infty<c<d<\infty$. Let $w$ be a weight function over $[c, d]$. The 3 -step linear kernel with respect to $w$ is denoted by $G_{w}$, and is defined as follows:

$$
G_{w}(x, t)=\left\{\begin{array}{cc}
\int_{c}^{t} w(u) d u, & t \in[c, x] \\
\int_{c}^{t} w(u) d u-\frac{1}{2} \int_{c}^{d} w(u) d u, & t \in(x, c+d-x], \\
\int_{d}^{t} w(u) d u, & t \in(c+d-x, d]
\end{array}\right.
$$

for $x \in\left[c, \frac{c+d}{2}\right]$ and $t \in[0,1]$.

The following lemma will be used repeatedly throughout the present paper.

Lemma 1. Let $-\infty<c<d<\infty$. For a weight function $w$ over $[c, d]$, the identity

$$
\begin{aligned}
& \int_{c}^{d} G_{w}(x, t) f^{\prime}(t) d t \\
& =\frac{1}{2}\left[\int_{c}^{d} w(t) d t\right][f(x)+f(c+d-x)] \\
& -\int_{c}^{d} w(t) f(t) d t,
\end{aligned}
$$


holds for all $x \in\left[c, \frac{c+d}{2}\right]$ and $t \in[0,1]$.

Proof. Using Definition 1, we have

$$
\begin{aligned}
\int_{c}^{d} G_{w}(x, t) f^{\prime}(t) d t= & \int_{c}^{x}\left[\int_{c}^{t} w(u) d u\right] f^{\prime}(t) d t \\
& +\int_{x}^{c+d-x}\left[\int_{c}^{t} w(u) d u-\frac{1}{2} \int_{c}^{d} w(u) d u\right] f^{\prime}(t) d t \\
& +\int_{c+d-x}^{d}\left[\int_{b}^{t} w(u) d u\right] f^{\prime}(t) d t .
\end{aligned}
$$

Applying integration by parts on each integral, we get

$$
\begin{aligned}
& \int_{c}^{x}\left[\int_{c}^{t} w(u) d u\right] f^{\prime}(t) d t=\left[\int_{c}^{x} w(u) d u\right] f(x)-\int_{c}^{x} w(t) f(t) d t \\
& \int_{x}^{c+d-x}\left[\int_{c}^{t} w(u) d u-\frac{1}{2} \int_{c}^{d} w(u) d u\right] f^{\prime}(t) d t \\
&=\left(\int_{c}^{c+d-x} w(u) d u-\frac{1}{2} \int_{c}^{d} w(u) d u\right) f(c+d-x) \\
&-\left(\int_{c}^{x} w(u) d u-\frac{1}{2} \int_{c}^{d} w(u) d u\right) f(x)-\int_{x}^{c+d-x} w(t) f(t) d t
\end{aligned}
$$

and

$$
\begin{aligned}
\int_{c+d-x}^{d}\left[\int_{d}^{t} w(u) d u\right] f^{\prime}(t) d t= & {\left[\int_{c+d-x}^{d} w(u) d u\right] f(c+d-x) } \\
& -\int_{c+d-x}^{d} w(t) f(t) d t .
\end{aligned}
$$


Thus,

$$
\begin{aligned}
& \int_{c}^{d} G_{w}(x, t) f^{\prime}(t) d t \\
& =\frac{1}{2}\left[\int_{c}^{d} w(t) d t\right][f(x)+f(c+d-x)] \\
& -\int_{c}^{d} w(t) f(t) d t .
\end{aligned}
$$

Remark 1. If we set $f(t)=t$ in Identity (2.2), we have

$$
\int_{c}^{d} G_{w}(x, t) d t=\frac{c+d}{2}\left[\int_{c}^{d} w(t) d t\right]-\int_{c}^{d} w(t) d t
$$

for $x \in\left[c, \frac{c+d}{2}\right]$.

Lemma 2. Let $-\infty<c<d<\infty$. If $w$ is a weight function over $[c, d]$, and $w$ is symmetric about $\frac{c+d}{2}$, then

$$
\int_{c}^{d} w(t) d t=\frac{c+d}{2}\left[\int_{c}^{d} w(t) d t\right]
$$

and hence

$$
\int_{c}^{d} G_{w}(x, t) d t=0
$$

for $x \in\left[c, \frac{c+d}{2}\right]$.

Proof. Since $w$ is symmetric about $\frac{c+d}{2}$,

$$
\int_{c}^{d} t w(t) d t=\int_{c}^{d}(c+d-t) w(t) d t,
$$

which implies that

$$
\int_{c}^{d} t w(t) d t=\frac{c+d}{2} \int_{c}^{d} w(t) d t
$$


Using Identity (2.3), we get that

$$
\int_{c}^{d} G_{w}(x, t) d t=0
$$

Theorem 3. Let $-\infty<c<d<\infty$ and $f:[c, d] \rightarrow \mathbb{R}$ be a differentiable function on $(c, d)$. Suppose that $w$ is a weight function over $[c, d]$. If $f^{\prime} \in L^{1}[c, d]$ and $B_{1} \leq f^{\prime}(t) \leq B_{2}$, for all $t \in[c, d]$, where $B_{1}, B_{2}$ are constants, then the inequality

$$
\begin{aligned}
& \mid\left[\frac{1}{2}\left(\int_{c}^{d} w(t) d t\right)(f(x)+f(c+d-x))-I(c, d, x) \cdot H(c, d)\right] \\
& \quad-\int_{c}^{d} w(t) f(t) d t \mid \\
& \leq \frac{1}{4} V(c, d, x)\left(B_{2}-B_{1}\right)(d-c)
\end{aligned}
$$

holds for all $x \in\left[c, \frac{c+d}{2}\right]$, where

$$
I(c, d, x)=\int_{c}^{d} G_{w}(x, t) d t, H(c, d)=\frac{f(d)-f(c)}{d-c},
$$

and

$$
V(c, d, x)=\max \left\{\int_{x}^{c+d-x} w(t) d t, \int_{c}^{d} w(t) d t-\int_{x}^{c+d-x} w(t) d t\right\}
$$

Proof. Note that for $t \in[0,1]$ and $x \in\left[c, \frac{c+d}{2}\right]$, we have

$$
L(c, d, x) \leq G_{w}(x, t) \leq U(c, d, x),
$$

where

$$
U(c, d, x)=\max \left\{\int_{c}^{x} w(t) d t, \quad \int_{c}^{c+d-x} w(t) d t-\frac{1}{2} \int_{c}^{d} w(t) d t\right\},
$$

and

$$
L(c, d, x)=\min \left\{\int_{c}^{x} w(t) d t-\frac{1}{2} \int_{c}^{d} w(t) d t, \int_{d}^{c+d-x} w(t) d t\right\}
$$


By Lemma 1, we have

$$
\begin{aligned}
& \frac{1}{d-c} \int_{c}^{d} G_{w}(x, t) f^{\prime}(t) d t-\frac{1}{(d-c)^{2}} \int_{c}^{d} G_{w}(x, t) d t \int_{c}^{d} f^{\prime}(t) d t \\
& =\frac{1}{2(d-c)}\left[\int_{c}^{d} w(t) d t\right][f(x)+f(c+d-x)] \\
& -\frac{f(d)-f(c)}{(d-c)^{2}} \int_{c}^{d} G_{w}(x, t) d t-\frac{1}{d-c} \int_{c}^{d} w(t) f(t) d t .
\end{aligned}
$$

Applying Grüss Inequality and using Identity (2.5), we get that

$$
\begin{aligned}
& \left|\frac{1}{d-c} \int_{c}^{d} G_{w}(x, t) f^{\prime}(t) d t-\frac{1}{(d-c)^{2}} \int_{c}^{d} G_{w}(x, t) d t \int_{c}^{d} f^{\prime}(t) d t\right| \\
& \leq \frac{1}{4}(U(c, d, x)-L(c, d, x))\left(B_{2}-B_{1}\right) .
\end{aligned}
$$

But

$$
U(c, d, x)-L(c, d, x)=V(c, d, x)
$$

which implies that

$$
\begin{aligned}
& \mid\left[\frac{1}{2}\left(\int_{c}^{d} w(t) d t\right)(f(x)+f(a+b-x))-I(c, d, x) \cdot H(c, d)\right] \\
& \quad-\int_{a}^{b} w(t) f(t) d t \mid \\
& \leq \frac{1}{4} V(c, d, x)\left(B_{2}-B_{1}\right)(d-c) .
\end{aligned}
$$

Corollary 1. Let $-\infty<c<d<\infty$ and $f:[c, d] \rightarrow \mathbb{R}$ be a differentiable function on $(c, d)$. Suppose that $w$ is a weight function over $[c, d]$ and $w$ is symmetric about $\frac{c+d}{2}$. If $f^{\prime} \in L^{1}[c, d]$ and $B_{1} \leq f^{\prime}(t) \leq B_{2}$, for all $t \in[c, d]$, where $B_{1}, B_{2}$ are constants, then the inequality

$$
\mid \frac{1}{2}\left(\int_{c}^{d} w(t) d t\right)(f(x)+f(c+d-x))
$$




$$
\begin{aligned}
& -\int_{c}^{d} w(t) f(t) d t \mid \\
\leq & \frac{1}{2} \max \left\{\int_{c}^{x} w(t) d t, \int_{x}^{\frac{c+d}{2}} w(t) d t\right\}\left(B_{2}-B_{1}\right)(d-c) \\
\leq & \frac{1}{2}\left(\int_{c}^{\frac{c+d}{2}} w(t) d t\right)\left(B_{2}-B_{1}\right)(d-c) .
\end{aligned}
$$

holds for all $x \in\left[c, \frac{c+d}{2}\right]$.

Proof. Note that for $t \in[0,1]$ and $x \in\left[c, \frac{c+d}{2}\right]$, we have

$$
\min \left\{\int_{x}^{c} w(t) d t, \int_{\frac{c+d}{2}}^{x} w(t) d t\right\} \leq G_{w}(x, t) \leq \max \left\{\int_{c}^{x} w(t) d t, \int_{x}^{\frac{c+d}{2}} w(t) d t\right\} .
$$

Applying Lemma 2, and following same argument used in the proof of Theorem 3 , the result follows.

Remark 2. If we set $w(t)=1$, Inequality 2.6 becomes same as Inequality 1.6 .

Theorem 4. Let $f: I \subset \mathbb{R} \rightarrow \mathbb{R}$ be a differentiable mapping on $I^{0}$, the interior of the interval $I$, and let $c, d \in I$ with $c<d$. Let $w$ be a weight function over $[c, d]$. If $f^{\prime} \in L^{1}[c, d]$ with $B_{1} \leq f^{\prime}(t) \leq B_{2}$ for all $t \in[c, d]$, where $B_{1}, B_{2}$ are constants, then for each $x \in\left[c, \frac{c+d}{2}\right]$, we have

$$
\begin{aligned}
& \mid\left[\frac{1}{2}\left(\int_{c}^{d} w(t) d t\right)(f(x)+f(a+b-x))\right. \\
& \left.\quad-\frac{\left(B_{1}+B_{2}\right)}{2} \cdot I(c, d, x)\right]-\int_{c}^{d} w(t) f(t) d t \mid \\
& \leq \frac{B_{2}-B_{1}}{2} \int_{c}^{d}\left|G_{w}(x, t)\right| d t .
\end{aligned}
$$


where $I(c, d, x)=\int_{c}^{d} G_{w}(x, t) d t$.

Proof. Using Lemma 1, we have

$$
\begin{aligned}
& \int_{c}^{d} G_{w}(x, t)\left(f^{\prime}(t)-\frac{B_{1}+B_{2}}{2}\right) d t \\
& =\frac{1}{2}\left[\int_{c}^{d} w(t) d t\right][f(x)+f(c+d-x)] \\
& -\frac{\left(B_{1}+B_{2}\right)}{2} \int_{c}^{d} G_{w}(x, t) d t-\int_{c}^{d} f(t) w(t) d t .
\end{aligned}
$$

Note that, for each $t \in[c, d]$,

which implies that

$$
\frac{B_{1}-B_{2}}{2} \leq f^{\prime}(t)-\frac{B_{1}+B_{2}}{2} \leq \frac{B_{2}-B_{1}}{2}
$$

$$
\max _{t \in[c, d]}\left|f^{\prime}(t)-\frac{B_{1}+B_{2}}{2}\right| \leq \frac{B_{2}-B_{1}}{2} .
$$

Thus,

$$
\begin{aligned}
& \left|\int_{c}^{d} G_{w}(x, t)\left(f^{\prime}(t)-\frac{B_{1}+B_{2}}{2}\right) d t\right| \\
& \leq \max _{t \in[c, d]}\left|f^{\prime}(t)-\frac{\left(B_{1}+B_{2}\right)}{2}\right| \int_{c}^{d}\left|G_{w}(x, t)\right| d t \\
& \leq \frac{\left(B_{2}-B_{1}\right)}{2} \int_{c}^{d}\left|G_{w}(x, t)\right| d t
\end{aligned}
$$

which implies that

$$
\begin{aligned}
& \left.\mid\left[\frac{1}{2} \int_{c}^{d} w(t) d t\right)(f(x)+f(c+d-x))-\frac{\left(B_{1}+B_{2}\right)}{2} \cdot I(c, d, x)\right] \\
& \quad-\int_{c}^{d} w(t) f(t) d t\left|\leq \frac{\left(B_{2}-B_{1}\right)}{2} \int_{c}^{d}\right| G_{w}(x, t) \mid d t .
\end{aligned}
$$


Corollary 2. Let $f: I \subset \mathbb{R} \rightarrow \mathbb{R}$ be a differentiable mapping on $I^{0}$, the interior of the interval $I$, and let $c, d \in I$ with $c<d$. Suppose that $w$ is a weight function over $[c, d]$ and $w$ is symmetric about $\frac{c+d}{2}$. If $f^{\prime} \in L^{1}[c, d]$ with $B_{1} \leq f^{\prime}(t) \leq B_{2}$ for all $t \in[c, d]$, where $B_{1}, B_{2}$ are constants, then for each $x \in[c, d]$, we have

$$
\begin{aligned}
& \left|\frac{1}{2}\left[\int_{c}^{d} w(t) d t\right][f(x)+f(c+d-x)]-\int_{c}^{d} f(t) w(t) d t\right| \\
& \leq \frac{B_{2}-B_{1}}{2} \int_{c}^{d}\left|G_{w}(x, t)\right| d t .
\end{aligned}
$$

Proof. Using Lemma 2 and applying Theorem 4, the result follows.

Theorem 5. Let $f: I \subset \mathbb{R} \rightarrow \mathbb{R}$ be a differentiable mapping on $(c, d) \subset I$. Suppose that $w$ is a weight function over $[c, d]$ and $w$ is symmetric about $\frac{c+d}{2}$. If $f^{\prime} \in$ $L^{1}[c, d]$ with $B_{1} \leq f^{\prime}(t) \leq B_{2}$ for all $t \in[c, d]$, where $B_{1}, B_{2}$ are constants, then for each $x \in\left[c, \frac{c+d}{2}\right]$, we have

$$
\begin{aligned}
& \left|\frac{1}{2}\left[\int_{c}^{d} w(t) d t\right][f(x)+f(c+d-x)]-\int_{c}^{d} f(t) w(t) d t\right| \\
& \leq(d-c)\left(\frac{f(d)-f(c)}{d-c}-B_{1}\right) \sup _{t \in[c, d]}\left|G_{w}(x, t)\right|,
\end{aligned}
$$

and

$$
\begin{aligned}
& \left|\left[\frac{1}{2} \int_{c}^{d} w(t) d t\right][f(x)+f(a+b-x)]-\int_{c}^{d} f(t) w(t) d t\right| \\
& \leq(d-c)\left(B_{2}-\frac{f(c)-f(d)}{d-c}\right) \sup _{t \in[c, d]}\left|G_{w}(x, t)\right| .
\end{aligned}
$$

Proof. Using Lemma 2

which implies that

$$
\int_{a}^{b} G_{w}(x, t) d t=0
$$

$$
\int_{c}^{d} G_{w}(x, t) f^{\prime}(t) d t=\int_{c}^{d} G_{w}(x, t) d t\left(f^{\prime}(t)-B_{1}\right) d t,
$$


and

$$
\int_{c}^{d} G_{w}(x, t) f^{\prime}(t) d t=\int_{c}^{d} G_{w}(x, t) d t\left(f^{\prime}(t)-B_{2}\right) d t .
$$

Using Lemma 1 and the triangle inequality we get

$$
\begin{aligned}
& \left|\frac{1}{2}\left[\int_{c}^{d} w(t) d t\right][f(x)+f(c+d-x)]-\int_{c}^{d} f(t) w(t) d t\right| \\
& \leq \int_{c}^{d}\left|G_{w}(x, t)\left(f^{\prime}(t)-B_{1}\right)\right| d t
\end{aligned}
$$

and

$$
\begin{aligned}
& \left|\frac{1}{2}\left[\int_{c}^{d} w(t) d t\right][f(x)+f(c+d-x)]-\int_{c}^{d} f(t) w(t) d t\right| \\
& \leq \int_{c}^{d}\left|G_{w}(x, t)\left(f^{\prime}(t)-B_{2}\right)\right| d t
\end{aligned}
$$

Note that

$$
\begin{aligned}
& \int_{c}^{d}\left|G_{w}(x, t) d t\left(f^{\prime}(t)-B_{1}\right)\right| d t \\
& \leq \sup _{t \in[c, d]}\left|G_{w}(x, t)\right| \int_{c}^{d}\left|f^{\prime}(t)-B_{1}\right| d t
\end{aligned}
$$

and

$$
\begin{aligned}
\int_{c}^{d}\left|f^{\prime}(t)-B_{1}\right| d t & =\int_{c}^{d}\left(f^{\prime}(t)-B_{1}\right) d t \\
& =f(d)-f(c)-B_{1}(d-c) \\
& =(d-c)\left[\frac{f(d)-f(c)}{d-c}-B_{1}\right]
\end{aligned}
$$

Similarly,

$$
\int_{c}^{d}\left|G_{w}(x, t)\left(f^{\prime}(t)-B_{2}\right)\right| d t
$$




$$
\leq \sup _{t \in[c, d]}\left|G_{w}(x, t)\right| \int_{c}^{d}\left|f^{\prime}(t)-B_{2}\right| d t .
$$

and

$$
\begin{aligned}
\int_{c}^{d}\left|f^{\prime}(t)-D_{2}\right| d t & =\int_{c}^{d} B_{2}-f^{\prime}(t) d t \\
& =B_{2}(d-c)-(f(d)-f(c)) \\
& =(d-c)\left[B_{2}-\frac{f(d)-f(c)}{d-c}\right] .
\end{aligned}
$$

Therefore,

$$
\begin{aligned}
& \left|\frac{1}{2}\left[\int_{c}^{d} w(t) d t\right][f(x)+f(c+d-x)]-\int_{c}^{d} f(t) w(t) d t\right| \\
& \leq(d-c)\left(\frac{f(d)-f(c)}{d-c}-B_{1}\right) \sup _{t \in[c, d]}\left|G_{w}(x, t)\right|,
\end{aligned}
$$

and

$$
\begin{aligned}
& \left|\frac{1}{2}\left[\int_{c}^{d} w(t) d t\right][f(x)+f(c+d-x)]-\int_{c}^{d} f(t) w(t) d t\right| \\
& \leq(d-c)\left(B_{2}-\frac{f(d)-f(c)}{d-c}\right) \sup _{t \in[c, d]}\left|G_{w}(x, t)\right| .
\end{aligned}
$$

\section{SOME APPLICATIONS}

Before introducing the first two applications, recall that a tagged partition $P$ of a finite interval $[c, d]$ is a finite sequence of numbers $c=x_{0}<x_{1}<\cdots<x_{n}=d$, with corresponding tags $t_{i} \in\left[x_{i-1}, x_{i}\right]$, for $i=1, \ldots, n$.

Theorem 6. Let $-\infty<c<d<\infty$ and $f:[c, d] \rightarrow \mathbb{R}$ be a differentiable function on $(c, d)$, and $P: c=x_{0}<x_{1}<\cdots<x_{n}=d$ be a tagged partition with corresponding values $t_{i} \in\left[x_{i-1}, \frac{x_{i-1}+x_{i}}{2}\right]$, for $i=1, \ldots, n$. Suppose that $w$ is a weight function over $[c, d]$. If $f^{\prime} \in L^{1}[c, d]$ and $B_{1} \leq f^{\prime}(t) \leq B_{2}$, for all $t \in[c, d]$, where $B_{1}, B_{2}$ are constants, then we have the quadrature formula

$$
\int_{c}^{d} w(t) f(t) d t=A(f, P)+R(f, P),
$$


where

$$
\begin{aligned}
A(f, P)= & \sum_{i=0}^{n-1}\left[\frac{1}{2} W\left(x_{i}, x_{i+1}\right)\left(f\left(t_{i+1}\right)+f\left(x_{i}+x_{i+1}-t_{i+1}\right)\right)\right. \\
& \left.-I\left(x_{i}, x_{i+1}, t_{i+1}\right) \cdot H\left(x_{i}, x_{i+1}\right)\right], \\
W\left(x_{i}, x_{i+1}\right) & =\int_{x_{i}}^{x_{i+1}} w(t) d t, 0 \leq i \leq n-1, \\
I\left(x_{i}, x_{i+1}, t_{i+1}\right) & =\int_{x_{i}}^{x_{i+1}} G_{w}\left(t_{i+1}, t\right) d t, 0 \leq i \leq n-1, \\
H\left(x_{i}, x_{i+1}\right) & =\frac{f_{\left(x_{i+1}\right)-f\left(x_{i}\right)}, 0 \leq i \leq n-1,}{x_{i+1}-x_{i}},
\end{aligned}
$$

and the remainder satisfies the inequality

$$
|R(f, P)| \leq \frac{\left(B_{2}-B_{1}\right)}{4} \sum_{i=0}^{n-1} V\left(x_{i}, x_{i+1}, t_{i+1}\right)\left(x_{i+1}-x_{i}\right),
$$

where

$$
V\left(x_{i}, x_{i+1}, t_{i+1}\right)=\max \left\{\int_{t_{i+1}}^{x_{i}+x_{i+1}-t_{i+1}} w(t) d t, W\left(x_{i}, x_{i+1}\right)-\int_{t_{i+1}}^{x_{i}+x_{i+1}-t_{i+1}} w(t) d t\right\}
$$

Proof. For each $0 \leq i \leq n-1$, applying Theorem 3 on $\left[x_{i}, x_{i+1}\right]$ with $x=t_{i+1}$, we get that

$$
\begin{aligned}
& \left|\int_{x_{i}}^{x_{i+1}} w(t) f(t) d t-\left[\begin{array}{c}
\frac{1}{2} W\left(x_{i}, x_{i+1}\right)\left(f\left(t_{i+1}\right)+f\left(x_{i}+x_{i+1}-t_{i+1}\right)\right) \\
-I\left(x_{i}, x_{i+1}, t_{i+1}\right) \cdot H\left(x_{i}, x_{i+1}\right)
\end{array}\right]\right| \\
& \leq \frac{\left(B_{2}-B_{1}\right)}{4} V\left(x_{i}, x_{i+1}, t_{i+1}\right)\left(x_{i+1}-x_{i}\right) .
\end{aligned}
$$

Using the triangle inequality, we find that

$$
\begin{aligned}
& \left|\sum_{i=0}^{n-1}\left(\int_{x_{i}}^{x_{i}+1} w(t) f(t) d t-\left[\begin{array}{c}
\frac{1}{2} W\left(x_{i}, x_{i+1}\right)\left(f\left(t_{i+1}\right)+f\left(x_{i}+x_{i+1}-t_{i+1}\right)\right) \\
-I\left(x_{i}, x_{i+1}, t_{i+1}\right) \cdot H\left(x_{i}, x_{i+1}\right)
\end{array}\right]\right)\right| \\
& \leq \frac{\left(B_{2}-B_{1}\right)}{4} \sum_{i=0}^{n-1} V\left(x_{i}, x_{i+1}, t_{i+1}\right)\left(x_{i+1}-x_{i}\right) .
\end{aligned}
$$


But

$$
\sum_{i=0}^{n-1} \int_{x_{i}}^{x_{i}+1} w(t) f(t) d t=\int_{c}^{d} w(t) f(t) d t
$$

which implies that

$$
\int_{c}^{d} w(t) f(t) d t=A(f, P)+R(f, P)
$$

and

$$
|R(f, P)| \leq \frac{\left(B_{2}-B_{1}\right)}{4} \sum_{i=0}^{n-1} V\left(x_{i}, x_{i+1}, t_{i+1}\right)\left(x_{i+1}-x_{i}\right)
$$

Theorem 7. Let $f: I \subset \mathbb{R} \rightarrow \mathbb{R}$ be a differentiable mapping on $I^{0}$, the interior of the interval $I, c, d \in I$ with $c<d$, and $P: c=x_{0}<x_{1}<\cdots<x_{n}=d$ be a tagged partition with corresponding values $t_{i} \in\left[x_{i-1}, \frac{x_{i-1}+x_{i}}{2}\right]$, for $i=1, \ldots, n$. Suppose that $w$ is a weight function over $[c, d]$. If $f^{\prime} \in L^{1}[c, d]$ with $B_{1} \leq f^{\prime}(t) \leq B_{2}$ for all $t \in[c, d]$, where $B_{1}, B_{2}$ are constants, then we have the quadrature formula

$$
\int_{c}^{d} w(t) f(t) d t=A(f, P)+R(f, P)
$$

where

$$
\begin{aligned}
A(f, P)=\sum_{i=0}^{n-1}\left[\frac{1}{2} W\left(x_{i}, x_{i+1}\right)\left(f\left(t_{i+1}\right)+f\left(x_{i}+x_{i+1}-t_{i+1}\right)\right)-B \cdot I\left(x_{i}, x_{i+1}, t_{i+1}\right)\right], \\
W\left(x_{i}, x_{i+1}\right)=\int_{x_{i}}^{x_{i+1}} w(t) d t, 0 \leq i \leq n-1, \\
i\left(x_{i}, x_{i+1}, t_{i+1}\right)=\int_{x_{i}}^{x_{i+1}} G_{w}\left(t_{i+1}, t\right) d t, 0 \leq i \leq n-1, \\
B=\frac{B_{1}+B_{2}}{2},
\end{aligned}
$$

and the remainder satisfies the inequality

$$
|R(f, P)| \leq \frac{\left(B_{2}-B_{1}\right)}{2} \sum_{i=0}^{n-1} Z\left(x_{i}, x_{i+1}, t_{i+1}\right),
$$


where

$$
Z\left(x_{i}, x_{i+1}, t_{i+1}\right)=\int_{x_{i}}^{x_{i+1}}\left|G_{w}\left(t_{i+1}, t\right)\right| d t .
$$

Proof. For each $0 \leq i \leq n-1$, applying Theorem 4 on $\left[x_{i-1}, x_{i}\right]$ with $x=t_{i+1}$, we get that

$$
\begin{aligned}
& \left|\int_{x_{i}}^{x_{i+1}} w(t) f(t) d t-\left[\begin{array}{c}
\frac{1}{2} W\left(x_{i}, x_{i+1}\right)\left(f\left(t_{i+1}\right)+f\left(x_{i}+x_{i+1}-t_{i+1}\right)\right) \\
-B \cdot I\left(x_{i}, x_{i+1}, t_{i+1}\right)
\end{array}\right]\right| \\
& \leq \frac{\left(B_{2}-B_{1}\right)}{2} \int_{x_{i}}^{x_{i+1}}\left|G_{w}\left(t_{i+1}, t\right)\right| d t \\
& =\frac{\left(B_{2}-B_{1}\right)}{2} Z\left(x_{i}, x_{i+1}, t_{i+1}\right) .
\end{aligned}
$$

Using the triangle inequality, we find that

$$
\begin{aligned}
& \left|\sum_{i=0}^{n-1} \int_{x_{i}}^{x_{i+1}} w(t) f(t) d t-\left[\begin{array}{c}
\frac{1}{2} W\left(x_{i}, x_{i+1}\right)\left(f\left(t_{i+1}\right)+f\left(x_{i}+x_{i+1}-t_{i+1}\right)\right) \\
-B \cdot I\left(x_{i}, x_{i+1}, t_{i+1}\right)
\end{array}\right]\right| \\
& \leq \frac{\left(B_{2}-B_{1}\right)}{2} \sum_{i=0}^{n-1} Z\left(x_{i}, x_{i+1}, t_{i+1}\right) .
\end{aligned}
$$

But

$$
\sum_{i=0}^{n-1} \int_{x_{i}}^{x_{i}+1} w(t) f(t) d t=\int_{c}^{d} w(t) f(t) d t
$$

and

which implies that

$$
\sum_{i=0}^{n-1} \int_{x_{i}}^{x_{i}+1}\left|G_{w}(x, t)\right| d t=\int_{c}^{d}\left|G_{w}(x, t)\right| d t
$$

$$
\int_{c}^{d} w(t) f(t) d t=A(f, P)+R(f, P)
$$

and

$$
|R(f, P)| \leq \frac{\left(B_{2}-B_{1}\right)}{2} \sum_{i=0}^{n-1} Z\left(x_{i}, x_{i+1}, t_{i+1}\right)
$$


Before we introduce the next application, recall that if $X$ is a random variable with values in a finite interval $[c, d], c<d$, and $f:[c, d] \rightarrow[0,1]$ is a probability density function, then the cumulative distribution function with respect to $f$ is denoted by $F$ and is defined as:

$$
F(x)=\int_{c}^{x} f(t) d t \text { for each } x \in[c, d] .
$$

Since $f$ satisfies the condition $\int_{c}^{d} f(x) d x=1, F(c)=1$.

Theorem 8. Let $X$ be a random variable with values in a finite interval $[c, d], c<$ $d$, and $f:[c, d] \rightarrow[0,1]$ be a probability density function. Let $w$ be a differentiable weight function over $[c, d]$ such that $w(d)=1$ and $w$ be symmetric about $\frac{c+d}{2}$. Let $F$ be the cumulative distribution function with respect to $f$. If $f \in L^{1}[c, d]$ and $B_{1} \leq f(t) \leq B_{2}$, for all $t \in[c, d]$, where $B_{1}, B_{2}$ are constants, then the inequality

$$
\begin{aligned}
& \left|\frac{1}{2}\left(\int_{c}^{d} w(t) d t\right)(F(x)+F(c+d-x))-\left(d-E_{G}\right)\right| \\
& \leq \frac{1}{4}\left[\int_{c}^{\frac{c+d}{2}} w(t) d t\right]\left(B_{2}-B_{1}\right)(d-c) .
\end{aligned}
$$

holds for all $x \in\left[c, \frac{c+d}{2}\right]$, where

$$
E_{G}=d-\int_{c}^{d} w(t) F(t) d t
$$

Proof. Define the function $G$ over $[c, d]$ as follows:

$$
G(x)=\int_{c}^{x} \frac{d}{d t}(w F) d t, x \in[c, d] .
$$

Note that

$$
G(c)=0
$$

and

$$
\begin{aligned}
G(d) & =\int_{c}^{d} \frac{d}{d t}(w F) d t \\
& =w(d) F(d)-w(c) F(c) \\
& =1
\end{aligned}
$$

Let

$$
E_{G}=\int_{c}^{d} t \frac{d}{d t}(w F) d t
$$


Using integration by parts, we get that

$$
\begin{aligned}
E_{G} & =d w(d) F(d)-c w(c) F(c)-\int_{c}^{d} w(t) F(t) d t \\
& =d-\int_{c}^{d} w(t) F(t) d t,
\end{aligned}
$$

which implies that

$$
\int_{c}^{d} w(t) F(t) d t=d-E_{G}
$$

Applying Corollary 1 on $F$, we get that

$$
\begin{aligned}
& \left|\frac{1}{2}\left(\int_{a}^{b} w(t) d t\right)(F(x)+F(c+d-x))-\int_{c}^{d} w(t) F(t) d t\right| \\
& \leq \frac{1}{4}\left[\int_{c}^{\frac{c+d}{2}} w(t) d t\right]\left(B_{2}-B_{1}\right)(d-c),
\end{aligned}
$$

which implies that

$$
\begin{aligned}
& \left|\frac{1}{2}\left(\int_{c}^{d} w(t) d t\right)(F(x)+F(c+d-x))-\left(d-E_{G}\right)\right| \\
& \leq \frac{1}{4}\left[\int_{c}^{\frac{c+d}{2}} w(t) d t\right]\left(B_{2}-B_{1}\right)(d-c) .
\end{aligned}
$$

\section{REFERENCES}

[1] M. Alomari, "A companion of ostrowski's inequality for mappings whose first derivatives are bounded and applications numerical integration." Kragujevac Journal of Mathematics, vol. 36, pp. 77-82, 2012.

[2] S. Dragomir, "Some companions of Ostrowski's inequality for absolutely continuous functions and applications." Bulletin of the Korean Mathematical Society, vol. 40, no. 2, pp. 213-230, 2005.

[3] S. Dragomir and S. Wang, "An inequality of Ostrowski-Grüss type and its applications to the estimation of error bounds for some special means and for some numerical quadrature rules," Computers and Mathematics with Applications, vol. 33, no. 11, pp. 15-20, 1997.

[4] W. Liu, "New Bounds for the Companion of Ostrowski's Inequality and Applications," Filomat, vol. 28, no. 1, pp. 167-178, 2014.

[5] D. Mitrinvić, J. Pecarić, and A. Fink, Classical and New Inequalities in Analysis. Dordrecht: Kluwer Academic Publishers, 2013. 
[6] A. Ostrowski, "Über die Absolutabweichung einer differentienbaren Funktionen von ihren Integralimittelwert," omment. Math. Hel., vol. 10, pp. 226-227, 1938.

[7] A. Rafiq and N. Mir, "An Ostrowski Type Inequality For p-norms," Journal of Inequalities in Pure and Applied Mathematics, vol. 7, no. 3, 2006.

[8] F. Zafar and N. Mir, "A Generalization of Ostrowski-gruss Type Inequality for First Differentiable Mappings," Tamsui Oxford Journal of Mathematical Sciences, vol. 26, no. 1, pp. 61-76, 2010.

Authors' addresses

\section{S. Obeidat}

Department of Basic Sciences, University of Hai'l, Saudi Arabia

E-mail address: obeidat sofianegmail.com

\section{A. Latif}

Department of Basic Sciences, University of Hai'l, Saudi Arabia

E-mail address: muhammad.mlatif@gmail.com

\section{A. Qayyum}

Department of Mathematics, Institute of Southern Punjab, Pakistan

E-mail address: atherqayyum@gmail.com 